\title{
Absorption Activity of Blood Neutrophils of Calves in Different using Schemes of Protamine
}

\author{
${ }^{1}$ Krapivina Elena Vladimirovna, ${ }^{2}$ Volkova Elena Alekseevna, \\ ${ }^{3}$ Ivanov Dmitry Valerievich
}

\begin{abstract}
${ }^{1}$ Doctor of biological sciences, professor, a citizen of the Russian Federation, Head of the Chair of epizootiology, microbiology, parasitology and veterinary-sanitary expertise of federal state budgetary educational institution of higher education "Bryansk State Agrarian University" (243365, Bryansk region., Vygonichsky district, village Kokino, Sovetskaya st.

${ }^{2}$ A citizen of the Russian Federation, postgraduate student of federal state budgetary educational institution of higher education "Bryansk State Agrarian University" (243365, Bryansk region., Vygonichsky district, village Kokino, Sovetskaya st.

${ }^{3}$ A citizen of the Russian Federation, candidate of biological sciences, veterinary doctor of the educational veterinary clinic of federal state budgetary educational institution of higher education "Bryansk State Agrarian University" (243365, Bryansk region., Vygonichsky district, village Kokino, Sovetskaya st.
\end{abstract}

\begin{abstract}
Annotation: To study the ability of neutrophils of calves' blood to absorb a foreign material, under different patterns of protamine use, 3 groups of 10 animals were formed. Group 1 calves were control, calves of 2 and 3 groups were experienced and received a feed additive of 14 grams per head for 2 months daily. Animals of the 2 group received a feed additive twice a day for 7 grams / head, and calves of the $3 \mathrm{rd}$ group - once a day for 14 grams / head. It was found that feeding the feed additive has an optimizing effect on the calves' homeostasis, but depending on the scheme of its use, various mechanisms of the absorptive function of blood neutrophils are activated. The greatest efficacy of the drug was established by feeding it twice a day at half the daily dose: within 1 month this contributed to an increase in the adaptive reserve of the absorptive capacity of neutrophils in calves' blood; - within 2 months, the absence of the need to increase the number of neutrophils in the blood for the safe state of the body; - 1 month after the end of feeding the drug caused an increase in AP and PI in stimulated conditions.
\end{abstract}

Keywords: calves, feed additive, blood, absorption ability of neutrophils.

Abbreviations: PS, \% - phagocytic significative; PI c.u. - Phagocytic index; AP $10^{9} / l$ - the absolute phagocytosis of blood; The PN, c.u. - Phagocytic number; bas. - Basal state - in blood stabilized with heparin; stim. - Stimulated state - after the introduction in the blood sample zymosan.

\section{INTRODUCTION}

Along with the humoral factors of nonspecific protection of the animal organism (lysozyme, properdin, complement, etc.), an important place in maintaining homeostasis is the phagocytic reaction of neutrophilic phagocytes. Phagocytosis as a factor of nonspecific protection manifests itself when pathogens penetrate the body. According to A.I. Trubkin (2011) after $30 \mathrm{~min}$., after the introduction of mycobacteria, an increase in phagocytic activity of leukocytes was observed with respect to mycobacteria in all animal species [1]. Obtained by V.N. Laskavym (2006) results indicate a significant effect of the percentage of neutrophils participating in phagocytosis (\% of PHAG) and their absorption capacity (FI) for the protecting animals from tuberculosis. [2]. To determine the functional activity of phagocytes, an estimation of the absorptive capacity of cells is carried out [3].

To increase the phagocytic activity of neutrophils, biologically active substances are often used. An increase in the number of neutrophils capable of absorbing foreign material in cows with pododermatitis was noted with the use of extract from the Lakonos [4]. It was found that Maksidin 0.4 has pronounced immunomodulatory, interferon-inducing and antiviral activity, stimulates the body's natural resistance, increases macrophage activity, is a detoxicant [5]. Some medicinal forms of Lobel's healers at therapeutic doses stimulate phagocytosis [6]. 
At the same time, the effectiveness of biologically active drugs with respect to increasing the activity of phagocytosis depends on the condition of the animal [7, 8], the dosage form of the preparation [9], the scheme of its use [10] and the age of the animals [11].

Feed additive of yeast hydrolyzate "Protamine" is obtained by enzymatic hydrolysis of yeast biomass of baker's or beer yeast with subsequent spray drying. "Protamine" does not contain any additives and preservatives. It has a full complex of interchangeable and irreplaceable amino acids, higher and lower peptides, B vitamins, polysaccharides, dietary fibers, micro- and macro elements corresponding to the composition of yeast biomass. In connection with the deep hydrolysis of cell protoplasmic proteins, as well as the deep depolymerization of cell wall and nucleic acid polysaccharides, this preparation possesses high digestibility [12].

The aim of the experiment was to study the absorption capacity of neutrophils in the blood of calves under using various schemes of protamine.

\section{MATERIALS AND METHODS}

To solve this problem, three groups of 10 calves of black and motley breed 1-1.5 months old with a live weight of $56.17 \pm 1.86 \mathrm{~kg}$ were formed in the JSC "Uchkhoz "Kokino" taking into account the breed, age and live weight using the method of paired analogs. The animals of the 1st group were control, the calves of the 2 nd and 3 rd groups were experienced and received the feed additive "Yeast hydrolyzate" Protamine "at 14 grams / head for 2 months daily. Animals of the 2 group received a feed additive twice a day for 7 grams / head, and calves of the 3rd group - once a day for 14 grams / head. Calves were kept in accordance with the veterinary-zooguyenic requirements and received an economic diet in accordance with generally accepted norms [13]. Blood for the study was taken from 5 animals from each group from the jugular vein in the morning before feeding before the start of the experiment, after 1 and 2 months of the drug application, and also one month after the end of feeding.

The hemogram values were calculated using the "Abacus junior vet 5 hemanalizer" and analysis of blood smears from experimental animals stained by Romanovsky-Giemsa (300 cells per smear). The phagocytic significative (PS,\%) was calculated as the percentage of neutrophils capable of absorbing latex particles, the phagocytic index (PI, cu) is the average number of latex particles absorbed by one active neutrophil, absolute phagocytosis of blood (AP, $10^{9} / \mathrm{L}$ ) Total number of latex particles absorbed by neutrophils in a liter of blood, phagocytic number - (PN, cu) - the average number of latex particles absorbed by one neutrophil (both active and inactive) [14]. Absorption capacity of neutrophils (PS, \%, PI, cu, AP, $10^{9} / \mathrm{L}, \mathrm{PN}$, cu) was evaluated in two states: basal (basal) - in freshly absorbed blood stabilized with heparin, and stimulated (Stim. ) - after inserting into the blood samples of zymosan, which simulates the conditions of bacterial infection and characterizes the adaptive reserves of the absorptive capacity of neutrophilic granulocytes [15].

The obtained digital data is processed by the method of variational statistics. To reveal statistically significant differences, the Student's test was used [16], significantly significant changes were counted, starting with $\mathrm{p}<0.05$. The values of the physiological norm were taken as the intervals of the corresponding indices given in the literature $[14,17,18]$.

\section{RESULTS OF THE STUDY AND THEIR DISCUSSION}

As a result of studying the obtained data, it was established that the absolute number of leukocytes in the blood of animals of all experimental groups did not change significantly during the experimental period, there were no differences between the groups. The absolute and relative quantity of blood neutrophils in the blood in animals of all experimental groups fluctuated within the limits of the standard values during the experimental period. At the same time, after 1 month of the experimental period, both the relative and absolute number of blood neutrophils in the calves of groups 2 and 3 was significantly lower than in the control ones (by 48.65 and $39.42 \%$, and by 54.37 and $48.09 \%$ respectively).

After 2 months of feeding the drug, the relative amount of blood neutrophils in calves of only 2 group was significantly lower (by 27.34\%) than in control animals. One month after the end of feeding the drug, there were no significant intergroup differences in the absolute and relative amounts of blood neutrophils in the blood of the animals of all the experimental groups. Consequently, the feeding of the drug for a month (according to both schemes) led to a high level of all the protective mechanisms of the body and the lack of the need to increase the number of neutrophils in the blood for a safe state 
of the body. The two-month feeding of protamine had a similar effect only with a scheme that uses the drug twice a day at half the daily dose.

PS in basal conditions in calves of all experimental groups during the experimental period was higher than the normative values, which indicates the presence of factors that activate blood neutrophils in the body, there was no intergroup difference in the value of this indicator. The exception was a significantly higher AP in calves of group 3 after 2 months of the experimental period compared to the control (by $30.64 \%$ ), which indicates a higher reactivity of blood neutrophils in calves who received the drug in full dose once a day.

The AP of blood neutrophils after stimulation by zymosan in calves of experimental groups had no intergroup differences before the beginning of the experiment, in animals of Groups 1 and 2 slightly exceeded the values of AP in basal conditions, and only in calves of the third group significantly exceeded these values by $33.23 \%$, which Indicates the presence in the calves of this group of the adaptive reserve of neutrophils of blood capable of absorbing foreign material.

Table. Influence of feeding the feed additive "Protamine" on the phagocytic activity of blood neutrophils in calves

\begin{tabular}{|c|c|c|c|c|c|}
\hline Indices & $\begin{array}{l}\text { Groups, } \\
\text { number of } \\
\text { animals }\end{array}$ & Before feeding & $\begin{array}{l}\text { After } 1 \text { month of } \\
\text { the experimental } \\
\text { period }\end{array}$ & $\begin{array}{l}\text { After } 2 \text { months of } \\
\text { the experimental } \\
\text { period }\end{array}$ & $\begin{array}{l}\text { One month after } \\
\text { the end of feeding }\end{array}$ \\
\hline \multirow{3}{*}{$\begin{array}{l}\text { Leukocytes, } \\
10^{9} / 1\end{array}$} & $1, n=5$ & $7,82 \pm 1,08$ & $9,86 \pm 1,18$ & $8,75 \pm 0,76$ & $8,68 \pm 1,57$ \\
\hline & $2, n=5$ & $6,88 \pm 0,60$ & $8,78 \pm 0,35$ & $9,74 \pm 0,51$ & $12,80 \pm 0,85$ \\
\hline & $3, n=5$ & $8,92 \pm 1,24$ & $8,12 \pm 0,46$ & $9,55 \pm 1,04$ & $10,96 \pm 0,53$ \\
\hline \multirow[t]{3}{*}{ Neutrophils, \% } & $1, \mathrm{n}=5$ & $25,82 \pm 4,15$ & $45,92 \pm 4,85$ & $33,58 \pm 2,29$ & $29,50 \pm 3,93$ \\
\hline & $2, n=5$ & $24,94 \pm 4,88$ & $23,58 \pm 4,94 *$ & $24,40 \pm 2,66^{*}$ & $40,10 \pm 4,96$ \\
\hline & $3, n=5$ & $37,06 \pm 6,93$ & $27,82 \pm 4,04^{*}$ & $29,92 \pm 1,14$ & $27,68 \pm 4,35$ \\
\hline \multirow{3}{*}{$\begin{array}{l}\text { Neutrophils, } \\
10^{9} / 1\end{array}$} & $1, n=5$ & $2,07 \pm 0,41$ & $4,47 \pm 0,38$ & $2,97 \pm 0,38$ & $2,65 \pm 0,72$ \\
\hline & $2, n=5$ & $1,75 \pm 0,47$ & $2,04 \pm 0,42 *$ & $2,40 \pm 0,33$ & $5,19 \pm 0,88$ \\
\hline & $3, \mathrm{n}=5$ & $3,60 \pm 1,13$ & $2,32 \pm 0,47 *$ & $2,95 \pm 0,67$ & $2,97 \pm 0,36$ \\
\hline \multirow[t]{3}{*}{ PSbas., \% } & $1, \mathrm{n}=5$ & $46,46 \pm 7,27$ & $55,20 \pm 7,10$ & $48,60 \pm 5,16$ & $42,10 \pm 4,22$ \\
\hline & $2, n=5$ & $49,19 \pm 2,16$ & $61,10 \pm 0,90$ & $60,80 \pm 2,56$ & $50,50 \pm 3,01$ \\
\hline & $3, n=5$ & $47,70 \pm 2,11$ & $67,90 \pm 1,27$ & $67,10 \pm 1,96 *$ & $55,00 \pm 2,66^{*}$ \\
\hline \multirow[t]{3}{*}{ PSstim., \% } & $1, n=5$ & $62,35 \pm 2,43$ & $53,50 \pm 5,52$ & $46,50 \pm 2,00$ & $41,50 \pm 2,82$ \\
\hline & $2, n=5$ & $53,46 \pm 4,33$ & $71,00 \pm 2,00 *$ & $52,60 \pm 2,34$ & $48,40 \pm 2,53$ \\
\hline & $3, n=5$ & $63,55 \pm 2,00$ & $65,50 \pm 0,96$ & $60,00 \pm 3,27 *$ & $50,80 \pm 2,49$ \\
\hline \multirow[t]{3}{*}{ PIbas., c.u. } & $1, \mathrm{n}=5$ & $5,02 \pm 0,30$ & $4,90 \pm 0,07$ & $4,62 \pm 0,28$ & $3,98 \pm 0,62$ \\
\hline & $2, n=5$ & $5,00 \pm 0,09$ & $5,48 \pm 0,24$ & $5,09 \pm 0,60$ & $5,27 \pm 0,16$ \\
\hline & $3, n=5$ & $4,64 \pm 0,20$ & $5,19 \pm 0,25$ & $5,39 \pm 0,15$ & $5,31 \pm 0,14$ \\
\hline \multirow{3}{*}{ PIstim., c.u. } & $1, n=5$ & $5,32 \pm 0,11$ & $4,78 \pm 0,09$ & $5,23 \pm 0,11$ & $4,57 \pm 2,82$ \\
\hline & $2, n=5$ & $5,26 \pm 0,23$ & $4,68 \pm 0,69$ & $5,63 \pm 0,27$ & $5,35 \pm 0,08 *$ \\
\hline & $3, n=5$ & $5,26 \pm 0,16$ & $4,81 \pm 0,23$ & $6,16 \pm 0,37$ & $5,19 \pm 0,29$ \\
\hline \multirow[t]{3}{*}{ APbas., $10^{9} / 1$} & $1, \mathrm{n}=5$ & $5,34 \pm 1,12$ & $12,50 \pm 2,58$ & $6,25 \pm 1,24$ & $3,87 \pm 0,89$ \\
\hline & $2, n=5$ & $4,37 \pm 1,33$ & $5,96 \pm 0,85$ & $7,28 \pm 1,17$ & $14,00 \pm 2,53^{*}$ \\
\hline & $3, n=5$ & $8,27 \pm 2,89$ & $8,29 \pm 0,85$ & $10,42 \pm 1,97$ & $8,68 \pm 1,17 *$ \\
\hline \multirow[t]{3}{*}{ APstim., $10^{9} / 1$} & $1, n=5$ & $7,00 \pm 1,53$ & $11,58 \pm 2,23$ & $6,76 \pm 1,05$ & $4,83 \pm 1,18$ \\
\hline & $2, n=5$ & $4,45 \pm 0,73$ & $8,68 \pm 1,59$ & $6,96 \pm 0,76$ & $13,59 \pm 2,75^{*}$ \\
\hline & $3, n=5$ & $11,90 \pm 3,86$ & $7,43 \pm 1,65$ & $11,14 \pm 3,05$ & $7,97 \pm 1,42$ \\
\hline \multirow[t]{3}{*}{ PNbas., c.u. } & $1, \mathrm{n}=5$ & $2,14 \pm 0,45$ & $2,49 \pm 0,56$ & $2,28 \pm 0,33$ & $1,56 \pm 0,42$ \\
\hline & $2, n=5$ & $2,46 \pm 0,13$ & $3,31 \pm 0,19$ & $3,08 \pm 0,36$ & $2,66 \pm 0,22$ \\
\hline & $3, n=5$ & $1,81 \pm 0,39$ & $3,59 \pm 0,19$ & $3,05 \pm 0,23 *$ & $2,93 \pm 0,22 *$ \\
\hline \multirow[t]{3}{*}{ PNstim., c.u. } & $1, n=5$ & $3,32 \pm 0,14$ & $2,57 \pm 0,30$ & $2,43 \pm 0,14$ & $1,63 \pm 0,34$ \\
\hline & $2, n=5$ & $2,82 \pm 0,28$ & $3,31 \pm 0,50$ & $2,19 \pm 0,13$ & $2,57 \pm 0,12 *$ \\
\hline & $3, n=5$ & $3,33 \pm 0,04$ & $3,15 \pm 0,18$ & $3,67 \pm 0,20^{*}$ & $2,63 \pm 0,18^{*}$ \\
\hline
\end{tabular}

Notes: $*$ - $p<0,05$ in relation to 1 (control) group.

The PS of blood neutrophils under stimulated conditions in the control group calves did not change significantly during the experimental period and did not differ from the value of this value in the basal conditions, which indicates the lack of an adaptive reserve in calves of the control group. In calves of the 2 nd group, significantly higher values of AP of neutrophils of blood in stimulated conditions were 
established after 1 month of the experimental period, compared with both the beginning of the experiment (by $32.81 \%$ ), the control (32.71\%), and the value of AP in basal conditions In these animals (by 16.20\%). After 2 months of feeding the drug in calves of this group, there was a tendency to reduce AP in stimulated conditions by $25.91 \%$, and 1 month after the end of feeding - a significantly significant decrease in the value of this indicator by $31.83 \%$. The PS of neutrophils of blood under stimulated conditions in the calves of group 3 did not change significantly during the experimental period and did not exceed the value of the neutrophil PS in the basal conditions, which indicates the lack of an adaptive reserve of blood neutrophils capable of absorbing foreign material. However, after 2 months of the experimental period, the PS of neutrophils of blood under stimulated conditions in the calves of group 3 was significantly higher than in the animals of the control group. Consequently, 2-fold feeding over half the daily dose of the drug during the month contributed to an increase in the adaptive reserve of the absorptive capacity of neutrophils in the blood of calves. Longer feeding of the drug according to this scheme did not cause the same effect. Two-month feeding of calves to a full dose of the drug once a day did not contribute to the creation of an adaptive reserve for the absorption capacity of neutrophils in the blood of calves, but provided a higher number of neutrophils capable of absorbing foreign material under basal and stimulated conditions, and also one month after the end of feeding the drug - under basal Conditions, than in the calves of the control group.

PI of neutrophils in the basal conditions in the blood in the calves of the experimental groups corresponded to the normative values before the beginning of the experiment without significant intergroup differences and did not change significantly during the experimental period.

PI of The blood neutrophil counts after stimulation with zymosan before the beginning of the experiment in calves of all groups were below the normative values without significant intergroup difference. Feeding the drug for 1 and 2 months had no significant effect on the magnitude of the PI neutrophil blood of calves in stimulated conditions. The adaptive reserve of the intensity of the absorptive capacity of blood neutrophils was absent in calves of all groups throughout the entire experiment. At the same time, 1 month after the end of feeding the preparation PI of blood neutrophils under stimulated conditions, the calves of group 2 were significantly higher than in the control animals. Consequently, feeding to calves for 2 months of the drug twice a day at half the dose caused an increase in the intensity of absorption of latex particles by blood neutrophils after stimulation with zymosan.

Absolute phagocytosis in basal and stimulated blood conditions in calves of experimental groups before the beginning of the experiment and during 2 months of feeding the preparation had no significant intergroup differences with the presence of high individual variability. However, 1 month after the end of feeding the preparation, the AP value in basal conditions in calves of 2 and 3 groups was significantly higher than in control animals (by 261.76 and $124.29 \%$, respectively). In the stimulated conditions AP was higher than in the control calves only in animals of the 2 nd group (by $181.37 \%$ ). Therefore, the feeding of the drug for both regimens determined an increase in AP in basal conditions 1 month after the end of its use, and under stimulated conditions this increase was observed only in calves that received the feed supplement twice a day in a half dose.

PN in basal and zymosan-stimulated conditions in calves of experimental groups before the beginning of the experiment and after 1 month had no significant intergroup differences. After 2 months of the experiment and 1 month after the end of feeding the preparation of PN both in basal and in zymosanstimulated conditions, the calves of group 3 were higher $(\mathrm{p}<0.05)$ than in control animals (by 33.77 and $87.82 \%$ respectively). In calves of group 2, this effect was detected only 1 month after the end of feeding the drug (57.67\% higher than in control animals). Consequently, feeding the drug in a full dose once a day for 2 months provides an increase in intensity (averaged by both active and inactive neutrophils) of neutrophil absorption by a foreign material, and according to the scheme - twice a day for half the dose - only after 1 month After the end of the use of the drug.

Thus, the feeding of the feed preparation "Protamine" had an optimizing effect on the calves' homeostasis, but depending on the scheme of its use, individual mechanisms of absorption of a foreign material by neutrophils of blood were activated.

Feeding the drug on both regimens for a month determined the high level of all the protective mechanisms of the body and the lack of the need to increase the number of neutrophils in the blood 
for a safe state of the organism, and also 1 month after the end of its use - an increase in AP in the basal conditions and PN in the conditions stimulated by zymosan.

Feeding the drug twice a day for half the daily dose of the drug:

- within 1 month - promoted an increase in the adaptive reserve of the absorptive capacity of blood neutrophils in calves;

- within 2 months - caused the absence of the need to increase the number of neutrophils in the blood for a safe state of the organism;

- 1 month after the end of feeding the drug caused the increase in AP and PI in stimulated conditions.

Feeding a full dose of the drug once a day:

- within 2 months - provided higher PS and PN in basal and stimulated conditions;

- 1 month after the end of feeding the drug caused an increase in PS and PN in basal conditions.

\section{REFERENCES}

[1] Trubkin A.I., Kharitonov M.V. Phagocytic activity of peripheral blood leukocytes in different animal species. Scientific notes of the Kazan State Veterinary Academy. N.E. Bauman. - 2011. T. 208 C. 238-244. (Style of Proceedings of conferences)

[2] Laskavy V.N. Completed phagocytosis is the basis of specific prevention of tuberculosis in cattle. Veterinary pathology. - 2006. - No. 3. - P. 140-142. (Article type in the journal)

[3] Miftakhova A.M. Phagocytosis and evaluation of its disorders. International Journal of Applied and Fundamental Research. - 2012. №1 C. 74. (Type of article in the magazine)

[4] Gugkayeva M.S., Chekhodaridi F.N. Comparative effectiveness of purulent pododermatitis treatment in cows. Izvestiya Gorsky State Agrarian University. - 2010. - T. 47. - No. 1. - P. 100103. (Article type in the journal)

[5] Topuria G.M., Esaskinab A.B. Effect of Maxidin 0.4 on the maintenance of immunocompetent blood cells in cattle. Proceedings of the Orenburg State Agrarian University. 2014. No. 4 (48) pp. 90-93. (Article type in the journal)

[6] Nikolayenko I.P. Natural resistance to the use of drugs kegeritsy lobel. Scientific notes of the educational institution "Vitebsk Order of the Badge of Honor" State Academy of Veterinary Medicine. " - 2013. - T.49 - № 2-2 C. 82-86. (Article type in the journal)

[7] Terekhova Yu.V. Phagocytic activity of neutrophils in cows of different genotypes of stress resistance. Agricultural sciences and agro-industrial complex at the turn of the century. 2015. №10. - P. 146-150. (Article type in the journal)

[8] Mannapova R.T., Rapiev R.A. Indicators of the immune response in the animal organism as adaptive-regulatory mechanisms for stress. Fundamental research. - 2014 No. 3-3 C. 500-504. (Article type in the journal)

[9] Rostovtseva Yu.V. Effect of complexes of biologically active compounds Coluria Geoides (Rosaceae) on phagocytosis. In the collection: Ecology of Southern Siberia and adjacent territories. In 2 volumes. - 2014. - P. 106-107. (Article type in the journal)

[10] Arkhipov A.V., Zakharchenko M.A., Krapivina E.V., Zakharchenko G.D., Krivopushkin AV Influence of arkutite feeding patterns on the level of natural resistance of the organism and productivity in calves. Bulletin BGSHA No. 3, 2011. - P. 52-57. (Article type in the journal)

[11] Ivanchenko M.O. Characteristics of immunoresistance in induced inflammatory process on the experimental model. Scientific notes of the Crimean Federal University named after V.I. Vernadsky. Biology. Chemistry. - 2014. No. 27-3 (66) P.43-50. (Article type in the journal)

[12] Yeast hydrolyzate "Protamine", specifications TU 9182-055-00334586-2007.(Type - specifications)

[13] Norms and rations of feeding of agricultural animals. Animals. / Reference Guide. The edition is revised and enlarged. Ed. Kalashnikova A.P., Fisinina V.I., Scheglova V.V. Moscow, 2003. 456 p. (Book Type) 
[14] Chumachenko V.E., Vysotsky A.M., Serdyuk N.A., Chumachenko V.V. Determination of natural resistance and metabolism in agricultural animals. - Kiev: Harvest, 1990.- 136 p. (Book Type)

[15] Khaitov R.B., Pinegin B.V., Istamov Kh.I. Ecological immunology. Moscow: VNIRO, 1995.219 p. (Book Type)

[16] Plokhinsky N.A. Biometrics. Publishing house of the Siberian Branch of the USSR Academy of Sciences. - Novosibirsk, 1961. - 362 p. (Book Type)

[17] Karput I.M. Hematologic atlas of agricultural animals. -Mn .: Uradzhai, 1986.- 183 p. (Book Type)

[18] Kondrakhin, I.P., Arkhipov A.V., Levchenko V.I., et al. Methods of veterinary and clinical laboratory diagnostics. Reference book / Ed. I.P. Kondrakhin. M.: KolosS., - 2004. - 250 p. (Book Type) 